\title{
An Ontology-Based Temporal Scheduling and Complexity Reduction Model for Timetabling Knowledge Management
}

\author{
Patience Usoro Usip*, Enobong Moses Umoren, Udoinyang Godwin Inyang, Mfonobong Maurice Ntekop
}

University of Uyo, Computer Science Department, Faculty of Science, 520003, Uyo, Nigeria

\begin{tabular}{l} 
A R T I C L E I N F O \\
\hline Article history: \\
Received: 04 June, 2017 \\
Accepted: 21 July, 2017 \\
Online: 24 August, 2017 \\
\hline Keywords: \\
Temporal Interval Relations \\
Formal Ontologies \\
Knowledge Management Systems \\
Optimal Time Scheduling \\
Timetabling Models
\end{tabular}

\section{Introduction}

This paper is an extension of work originally presented in the Future Technologies Conference 2016 [1], where the use of ontologies in semantic web was established as an efficient and intelligent tool for managing timetabling knowledge [2]. Domain specific concepts and some complexities were presented in figures 2, 3(a) and 3(b) of the conference paper. The Allen's interval-based temporal relations [3] were considered suitable and introduced for inferencing [4] in the sample rules used to describe possible resolutions to the highlighted complexities in the conference paper. Allen's interval-based temporal relations were introduced to handle time durations and is adapted or reused for formal description of time periods for complex knowledge management as seen in the timetable domain. However, this paper extends works done in the conference paper as it aims at formalizing an ontology model for analyzing temporal scheduling complexities in an existing schedule and providing optimal possible time scheduling resolutions showing their reduction rate for efficient and intelligent knowledge management.

\footnotetext{
*Corresponding Author: Patience Usoro Usip, Computer Science Department, University of Uyo, Uyo, +2348060546140, patiencebassey@uniuyo.edu.ng, patceeng@gmail.com
}

In recent years, the explicit formal specifications of terms in any given domain and relations among them have gradually moved from the realm of Artificial Intelligence (AI) laboratories to the desktops of domain experts. The representation of domain concepts in structural ways - definition of concepts (classes and properties) and mapping the relationships among the defined concepts, form the basis of Ontology [5]. From the computer science perspective, it is a formal naming and definition of the types, properties, and interrelationship of the entities that really or fundamentally exist for a particular domain of discourse [6] [7]. For example, in a lecture timetable domain, courses, timeslots, students, lecturers, venues and lectures are some of the concepts from which the timetabling application domain can be described. These concepts and their meanings together constitute ontology for timetable and can be used as common knowledge for communication among educational stakeholders and provides information for the development of a timetable information system.

Ontologies exist in diverse forms - lexicons, dictionaries, thesauri, and logical models described in languages such as first order logic (FOL). Lexicons provide standard lists of words 


\section{P. U. Usip et al. / Advances in Science, Technology and Engineering Systems Journal Vol. 2, No. 3, 1585-1591 (2017)}

(vocabulary) in a language with corresponding knowledge of how each word is used. Hence a lexicon can be seen as an index for mapping written form of a word with the information about that word [8]. Dictionaries can be organized to form hierarchiestaxonomies, meronomies, mereologies and merons, according to specific relations. Related terms, linguistics objects are added to any given collection of terms through thesauri. Ontologies provide standardization of the terms used to represent knowledge about a domain in any of these forms. They can as well support inference with FOL or its subset, by deriving new facts from a collection of facts and enforcement of consistency. It also allows for sharing common understanding of the structure of information among people or software agent; reuse of domain knowledge; making domain assumption explicit; separating domain knowledge from operational knowledge; and analyzing domain knowledge. These considerations are clearly useful for knowledge management, especially when large amounts of knowledge are being processed. Ontology is increasingly used in various fields such as Knowledge Engineering, Artificial Intelligence(AI) and computer science, in applications related to knowledge management (KM), natural language processing.

$\mathrm{KM}$ involves the acquisition, creation, use, representation, organization and advancement of knowledge in its many forms. As a requirement for effective $\mathrm{KM}$, an understanding of how individuals, groups and organizations use knowledge is needed. One major aspect of an organization that require effective management of knowledge is timetable scheduling. This is because an organization's general timetable exhibit different levels of temporal scheduling complexities depending on the available resources. The threats posed by these complexities ranges from poor organization performance as seen in the domain of discourse (poor academic performance). Knowledge management is thereby required in attempt to reduce these complexities. Automation of timetabling process as seen in existing systems [9] [10] [11] does not resolve these complexities. This paper demonstrates the application of ontologies in timetable KM. It is aimed at analyzing any existing temporal schedule to discover all complexities and providing possible temporal schedules with reduced complexities (in time and space requirement) that tends towards optimality. This is achieved by utilizing Allen's temporal interval relations described in the following sections and evaluating the resulting optimal temporal schedule for proof and the need for adoption.

\section{Formal Ontologies and Temporal Interval Relations}

The time ontology has been considered by several authors with unique contributions to issues relating to temporal (time) representation and reasoning among others. Hobbs and Pan [12] considered temporal relations (TR) involving two subclasses of time - time instant and time interval. Allen's interval relations $[13,3]$ centers on various time intervals and possible reasoning involving co-operating concepts. As proposed by Allen [3], a framework for temporal reasoning, and all the relations proposed dealt with the directionality of time. In his proposal, intervals are the only temporal primitives in the temporal logic. Allen aimed at illustrating natural language sentences and to represent plans. To achieve the thirteen (13) basic relations between time intervals, with six of the intervals being the inverse of the other six: before, after, finishes, finished-by, overlaps, overlapped-by, starts, started- by, during, contains, meets, met-by and equal [3]. The basic interval temporal relations (Figure 1). These temporal relations depict and relate the actions and plans described in this paper.

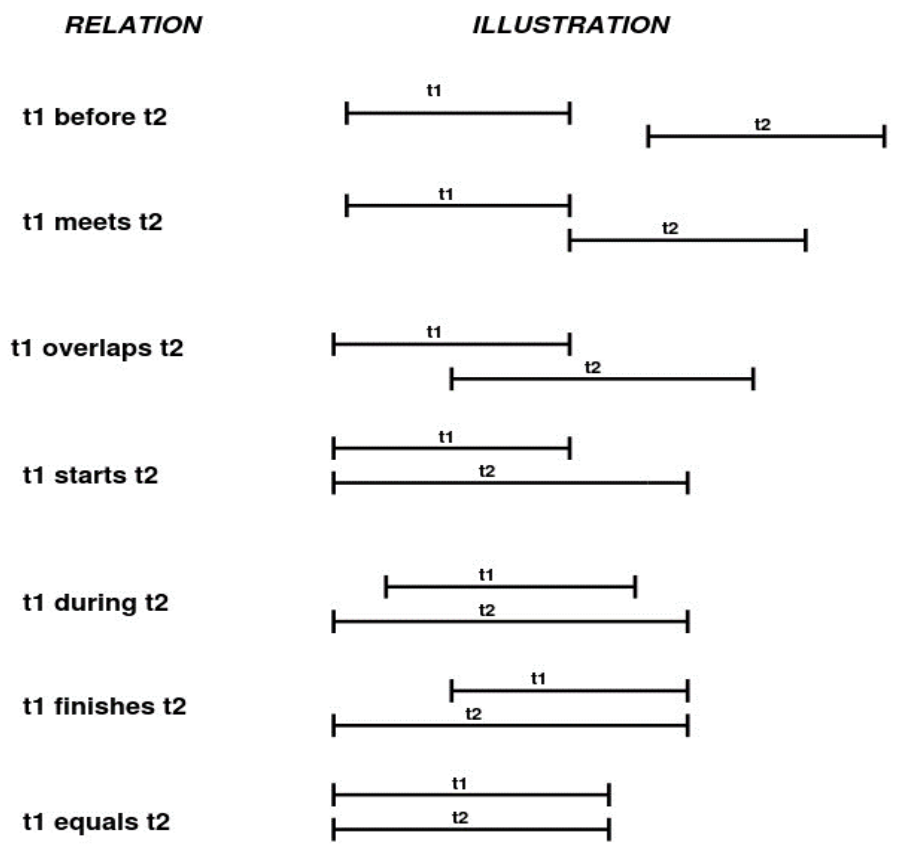

Figure 1: Allen's interval based temporal relations

This paper is targeted at formalizing the basic temporal ontology model for reasoning and inference towards an optimal time scheduling, after an analysis of an existing timetable to unravel all the complexities and evaluating feasible solutions towards achieving optimality. An illustration of how moment and point works on interval-based temporal logic is given in "moment and point in an interval based temporal logic". Moment is a nondecomposable period where the time is corresponding to instantaneous events while a point (a zero duration time) is where reasoning about the beginning and ending of event do arises. The axiomatization of the stated theory of time was done in terms of the simple relationship "meets" and subsumes the interval-based theory proposed in [3] thereby extending the theory to point-like time periods.

\section{Timetabling Complexities}

Timetable analysis reveals the major concepts - departments, timeslots, courses, students, venue and lecturers as objects responsible for complexities in timetable implementations. Three categories of courses exist in any typical higher institution; departmental, faculty-based and university-based courses. This paper considers the complexities arising from their interdependencies in scheduling the intra-departmental and interdepartmental (faculty-based and university-based) courses. Amongst other timetabling competency questions, are the following in the optimization of the general temporal scheduling ontology. They include: 
i. Is the course offered by other departments, other than the host department?

ii. Are other courses for the same level in all cooperating departments allocated to the same time?

iii. Are students in higher levels in the cooperating departments also offering the course?

iv. Is the course lecturer teaching another course allocated at the same time?

v. Is the venue for course far apart from venue of the preceding or succeeding courses (courses before or after)? That is, are the respective venue for teaching the courses on different campuses? or are they within the same campus but widely separated?

Each of these concepts has peculiar attributes. These concepts relate in diverse ways and some of the relations exist in reverse form. The relations include owns, has, can-be, offers, teaches, holds-in, lectures-in, and are-assigned-to. In consideration of the fact that most resources of the university (such as lecturer, venue, and courses) are shared and in some other cases limited, departments compete for these resources. A university has a given number of programmes running on specified number of campuses. Campuses or lecture venues widely separated far apart from each other will exhibit a high level of complexity with numerous interdependencies. A sample model in fig. 1 with the departmental general timetable ontology for each department was described in [1] and shown in the resulting ontograf (Figure 2) from protégé. Almost all the components of the ontology are shared, making it needful for interoperability amongst relating departments. An attempt to link the ontologies for all the relating departments will make the resulting ontology cumbersome and more complicated largely because components of the ontology are not owned by a department, the number of inter-dependencies will generate some form of conflict of interest.

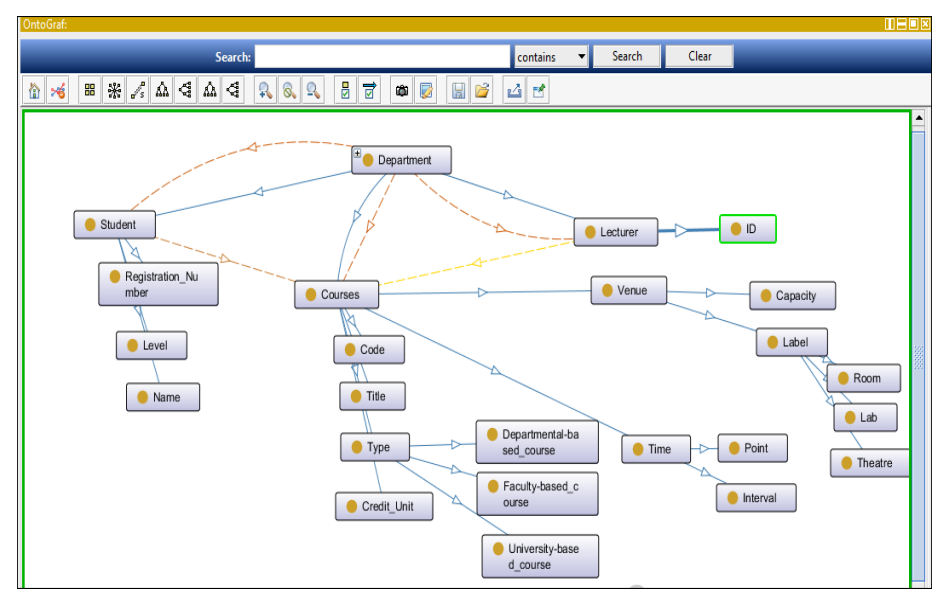

Figure 2: An Ontograf of a Departmental Timetable Ontology

Suppose course $c_{i}$ is to be taught by lecturer $\mathrm{L}_{\mathrm{l}}$, scheduled to hold at venue $v_{1}$ at time $t_{i}$ and another course $c_{j}$ to be taught be the same lecturer $L_{1}$ at same time $t_{i}$ in another venue $v_{2}$, exposes some form of complexities. Again, suppose $c_{i}$ and $c_{j}$ are both scheduled to hold at $\mathrm{v}_{1}$ at the same time $t_{i}$ bring to bear another level of complexity that is predominant in the domain. That is a groups of students offering a particular course holding at time $t_{1}$ at campus $\mathrm{U}_{1}$, and also offering another course $\mathrm{c}_{\mathrm{j}}$ holding at time $\mathrm{t}_{2}$ at campus $\mathrm{U}_{2}$, where time $t_{1}$ meets time $t_{2}$. The meeting time does not give allowance for the participating students to travel from campus $U_{1}$ to campus $U_{2}$ (or from venue vi to venue v2 with campus $U_{i}$ ). A general model of these complexities is shown in Figure 3.

A view of the various complexities based on the Allen's interval relations results in the following temporal complexity types: overlapping time (which also includes starts, ends and during relations) for courses taught by same lecturers and offered by same level of students. Meeting time complexity also results for courses offered by inter campus students. Other complexity types, not handled in this paper, include venue-clash and carrying capacity check.

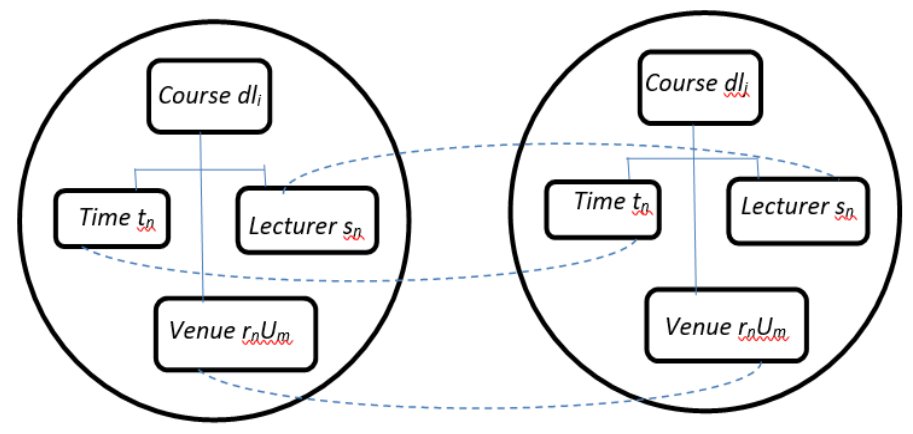

Figure 3: A course allocation complexity model

where $d$ is the department's code, $l$ is the level of students, $t$ represents the timeslot, $\mathrm{s}$ is the lecturer, $\mathrm{r}$ the room number while $\mathrm{U}$ is the campus. $i, j, n, m>0$ are instances of the various objects

From the general course allocation complexity model in Figure 3, several levels of complexity are defined to include:

- Departmental Complexity (Regular)

- Departmental Complexity (Carryover)

- Faculty-Based (Inter-Departmental)

Complexity (Regular)

- Faculty-Based (Inter-Departmental) Complexity (carryover)

- Inter-Faculty/Same Campus Complexities (Regular)

- Inter-Faculty/Same Campus Complexities (Carryover)

- Inter-Faculty/Inter-Campus Complexities

A generalized timetable ontology will expand the departmental timetable ontology is obtained from a mapped departmental timetable ontology as modeled in [1]. This require the mapping of domain resources ranging from, past results, course registration list, departmental brochure for details of all level courses and lecturers, campus location (or distance apart), etc.

Table 1 gives a justification of complexities in all the cases in consideration and the possible resolution based on interval temporal relations.

\section{System Framework}

Figure 4 gives the architecture of the proposed OntologyBased Temporal Scheduling Framework showing the relevant components for the achievement of its set goal of producing an optimal time schedule. 
Table 1: Complexity description by type and possible time scheduling resolution

\begin{tabular}{|c|c|c|c|}
\hline $\begin{array}{c}\text { Case } \\
\text { number }\end{array}$ & Case description & $\begin{array}{c}\text { Complexity } \\
\text { type }\end{array}$ & Resolution \\
\hline 1. & $\begin{array}{l}\text { Carryover } \\
\text { /repeating students } \\
\text { in the host } \\
\text { department. }\end{array}$ & $\begin{array}{l}\text { Overlappin } \\
\text { g- Time }\end{array}$ & $\begin{array}{l}\text { If carryover students are } \\
\text { offering course } c_{i} \text { at time } t_{1} \text {, then } \\
\text { time } t_{2} \text { for course } c_{j} \text { (time for } \\
\text { their level course should not } \\
\text { overlap). }\end{array}$ \\
\hline 2. & $\begin{array}{l}\text { Carryover / } \\
\text { repeating } \\
\text { students in the } \\
\text { serviced } \\
\text { department. }\end{array}$ & $\begin{array}{l}\text { Overlappin } \\
\text { g- Time }\end{array}$ & $\begin{array}{l}\text { If carryover students are } \\
\text { offering course } c_{i} \text { at time } t_{1} \text {, then } \\
\text { time } t_{2} \text { for course } c_{j} \text { (time for } \\
\text { their level course should not } \\
\text { overlap). }\end{array}$ \\
\hline 3. & $\begin{array}{l}\text { Regular students } \\
\text { (students at that } \\
\text { level) in the } \\
\text { services } \\
\text { department. }\end{array}$ & $\begin{array}{l}\text { Meeting- } \\
\text { Time }\end{array}$ & $\begin{array}{l}\text { If course } c_{i} \text { is scheduled at time } \\
t_{1} \text { in campus } U_{1} \text {, (for e.g } 10-12 \text { ) } \\
\text { and course } c_{j} \text { is also scheduled } \\
\text { at time } t_{2} \text { in campus } U_{2} \text {, where } \\
\text { the end-time of course } 1 c_{i} \text { meets } \\
\text { with the start-time of course } c_{j} \text {, } \\
\text { the course should be } \\
\text { rescheduled. }\end{array}$ \\
\hline 4. & $\begin{array}{l}\text { Assigning the } \\
\text { same lecturer to } \\
\text { teach at different } \\
\text { campuses, } \\
\text { without giving } \\
\text { sufficient time } \\
\text { interval. }\end{array}$ & $\begin{array}{l}\text { Meeting- } \\
\text { Time }\end{array}$ & $\begin{array}{l}\text { A lecturer assigned for course } c_{1} \\
\text { at time } t_{1} \text { in campus } U^{1} \text {, and also } \\
\text { assigned for course } c_{j} \text { at time } t_{2} \\
\text { in campus } U_{2} \text {, where the end- } \\
\text { time of course } c_{i} \text { meets with the } \\
\text { start-time of course } c_{j} \text {, should be } \\
\text { rescheduled. }\end{array}$ \\
\hline 5. & $\begin{array}{l}\text { students at same } \\
\text { level and } \\
\text { carryover/repeate } \\
\text { rs student in the } \\
\text { services } \\
\text { department. }\end{array}$ & $\begin{array}{l}\text { Starts/ } \\
\text { Finishes }\end{array}$ & $\begin{array}{l}\text { If course } c_{i} \text { and course } c_{j} \text { are of } \\
\text { different department, then } \\
\text { course } c_{j} \text { should not start at the } \\
\text { same time with course } 1 \text { and } \\
\text { finishes after course } c_{i}\end{array}$ \\
\hline 6. & $\begin{array}{l}\text { Students in their } \\
\text { regular year of } \\
\text { studies and } \\
\text { carryover student } \\
\text { of different } \\
\text { department, but } \\
\text { the same faculty. }\end{array}$ & During & $\begin{array}{l}\text { If course } c_{i} \text { and course } c_{j} \text { are of } \\
\text { different department, } d_{i} \text { and } d_{j} \\
\text { respectively, but of the same } \\
\text { faculty, then course } c_{i} \text { should not } \\
\text { hold during course } c_{j}\end{array}$ \\
\hline 7. & $\begin{array}{l}\text { Students (both } \\
\text { regular students } \\
\text { and carryover } \\
\text { student) at } \\
\text { another campus, } \\
\text { offering a course } \\
\text { holding at a } \\
\text { different campus. }\end{array}$ & $\begin{array}{l}\text { Location } \\
\text { Campus } \\
\text { location } \\
\text { (distance } \\
\text { apart) }\end{array}$ & $\begin{array}{l}\text { If course } c_{i} \text { is scheduled for time } \\
t_{1} \text { in campus } U_{1} \text {, and course } c_{j} \text { is } \\
\text { also scheduled for time } t_{2} \text { in } \\
\text { campus } U_{2} \text {, then time } t_{1} \text { should } \\
\text { not meet } t_{2}\end{array}$ \\
\hline 8. & $\begin{array}{l}\text { The class size } \\
\text { and the carrying } \\
\text { capacity of the } \\
\text { lecture venue. }\end{array}$ & $\begin{array}{l}\text { Space } \\
\text { (carrying } \\
\text { capacity) }\end{array}$ & $\begin{array}{l}\text { If the number of students } \\
\text { offering course } c_{i} \text { is greater than } \\
\text { the venue assigned, then course } \\
c_{i} \text { should be re-scheduled for a } \\
\text { bigger venue. }\end{array}$ \\
\hline
\end{tabular}

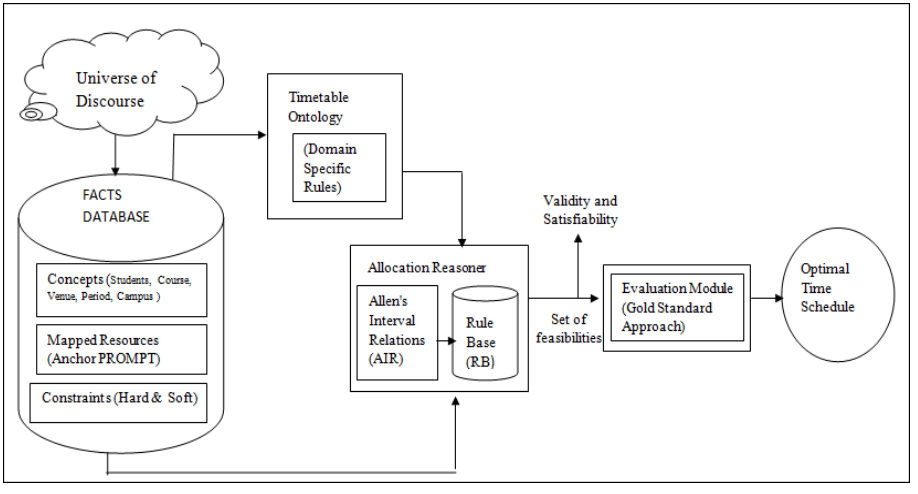

Figure 4: Architecture of the Proposed Ontology-Based Time Scheduling System
The major components of the system as depicted in Figure 4, are described as follows:

(i) Universe of Discourse: the universe of discourse where the domain knowledge under consideration is obtained. It consists of all the domain concepts - courses, venues, universities, timeslots, lecturers, students, students' status, departments, faculties, levels, campuses, locations, timetable and other aspects of the timetabling domain

(ii) Fact Database: this includes the values and instances of the domain concepts, the resources, relations and a mapping of facts to concepts and resources. It also has the hard and soft constraints.

(iii) Time Ontology; this component stores the domain specific rule (owns, has, offers etc.) which will be considered while mapping the resources.

(iv) Allocation Reasoner: this is where reasoning and inferencing take place based on the Allen's interval-based temporal relations. The sets of rules arising from the competency questions and some already established constraints, are also part of this component. the Allocation Reasoner works in collaboration with the domain specific rules.

(v) Ontology Evaluation Approach: Criteria from the gold or golden ontology evaluation standard helps in assessing the set of feasibilities obtained from the Allocation Reasoner towards optimality of the timetable.

(vi) Optimal Time Schedule: This gives the resulting possible time schedule showing the resolutions made towards optimality.

To manage the complexities called for the optimized general time schedule with an allocation reasoner with interval-based temporal relations operating in-between the cooperating departmental timetable ontologies. Shared components of the optimized general timetable ontology. The interval-based temporal relations/rules serve as the instrument for managing the identified complexities in the timetabling system. With the interval-based temporal relation allocation of courses to venues, allocation of courses to timeslots (time duration), and assignment of lecturers to courses/venues are efficiently done.

\subsection{Proposed Complexity Reduction Rules}

From competency questions (i) to (v) identified in section 3.0, rules $\mathrm{R} 1$ to $\mathrm{R} 12$ addresses the complexities as well as adopting the Allen's interval relations in the proposed resolutions. It is assumed that all departments within the same faculties are domicile in the same geo-location:

R1: IF student of department $d_{i}$ offers course $c_{i}$ AND department $d_{i}$ NOT owns course $c_{i}$ THEN time $t_{1}$ for course $c_{i}$ NOT overlaps time $t_{2}$ for course $c_{j}$ in department $d_{2}$.

R2: IF course $c_{i}$ holds at time $t_{1}$ and course $c_{j}$ holds at time $t_{2}$ AND $t_{1}$ equals $t_{2}$ AND students offer $c_{i}$ and $c_{j}$ THEN $t_{1}$ and $\mathrm{t}_{2}$ overlaps. 
P. U. Usip et al. / Advances in Science, Technology and Engineering Systems Journal Vol. 2, No. 3, 1585-1591 (2017)

R3: IF course $\mathrm{c}_{\mathrm{i}}$ holds at time $\mathrm{t}_{1}$ and course $\mathrm{c}_{\mathrm{j}}$ holds at time $\mathrm{t}_{2}$ AND time $t_{1}$ is during time $t_{2}$ AND students offer course $c_{i}$ and course $c_{j}$ THEN $t_{1}$ and $t_{2}$ overlaps.

R4: IF course $c_{i}$ holds at time $t_{1}$ and course $c_{j}$ holds at time $t_{2}$ AND $t_{1}$ starts with $t_{2}$ AND students offer $c_{i}$ and $c_{j}$ THEN $t_{1}$ and $t_{2}$ overlaps.

R5: IF course $c_{i}$ holds at $t_{1}$ and course $c_{j}$ holds at time $c_{2}$ AND $t_{1}$ finishes at $t_{2}$ AND students offer $c_{i}$ and $c_{j}$ THEN $t_{1}$ and $\mathrm{t}_{2}$ overlaps.

R6: IF $\mathrm{c}_{\mathrm{i}}$ and $\mathrm{c}_{\mathrm{j}}$ belongs to the same department, $\mathrm{d}_{1}$, THEN scheduled $c_{j}$ to $t_{i}$ AND $c_{j}$ to $t_{j}$ such that $t_{i} \neq t_{j}$ (NOT overlaps).

R7: IF $c_{i}$ and $c_{j}$ are of different department, $d_{i}$ and $d_{j}$ respectively, but of the same faculty, THEN time for $c_{i}$ should NOT overlaps with $c_{j}$ or $c_{i}$ NOT during $c_{j}$.

R8: $\quad$ IF $t_{i}$ for $c_{i}$ and $t_{2}$ for $c_{j}$ meets, THEN $t_{j}$ for $c_{j}$ will be changed and scheduled for another time (NOT meets)

R9: IF $c_{i}$ and $c_{j}$ are courses of different faculty, THEN their time NOT meets and NOT overlaps

R10: IF time for $c_{i}$ and $c_{j}$ are equals AND venue assigned for $c_{i}$ is the same venue assigned for $c_{j}$, THEN $\left(c_{i}\right.$ OR $\left.c_{j}\right)$ should be rescheduled for different time.

R11: IF time for $c_{i}$ and $c_{j}$ are equals or meets, AND the lecturer assigned for $c i$ in campus $U_{1}$ is also assigned for $c_{j}$ in $U_{2}$ within the time interval of one hour, THEN $c_{j}$ should be rescheduled for another time.

R12: IF $c_{i}$ is scheduled for $t_{i}$ in $U_{1}$ AND $c_{j}$ scheduled for $t_{j}$ in $U_{2}$ THEN $t_{i}$ NOT meets $\mathrm{tj}$.

R13: IF carryover/repeating students are offering $c_{i}$ scheduled for time $t_{i}$ THEN $t_{j}$, time for their level course, $c_{j}$ NOT overlaps $t_{i}$.

R14: IF $c_{i}$ in campus $U_{1}$ and course $c_{j}$ in $U_{2}$, THEN time $t_{i}$ for $c_{i}$ and $t_{j}$ for $c_{j}$ NOT meets or NOT overlaps.

R15: IF number of students offering $c_{i}$ is greater than the venue carrying capacity, THEN re-schedule $c_{i}$.

Formally expressing the above rules in FOL results in axioms A1 to A15. Recalling from the conceptualization of the domain concepts: student, lecturer, time, venue and campus with domain-specific relations: owns, has, offers, holds and teaches does not resolve time scheduling complexities when considering inter-departmental course allocation. This called for the adoption of the Allen's interval relations which includes temporal relations such as overlaps. meets, equals, during and their negations for a more explicit representation. Axioms A1 to A15 constitute the core of the ontology reasoner that results in the optimal time scheduling process.

\footnotetext{
A1: $\forall$ Student, Course1, Time1, Dept1 $\exists$ Course2, Time2, Dept2. offers(Student, Course1) ^ owns(Dept1, Course1)

$\wedge$ offers(Student, Course2)^owns(Dept2,Course2)

$\Rightarrow$ cooperates(Dept1, Host,Dept2, Serviced).
}

A2: $\quad \forall$ Student, Course1, Time1,Course2, Time2.

holds(Course1, Time1) ^ holds(Course2, Time2) ^ equals(Time1, Time2) $\wedge$ offers(Student, Course1) $\wedge$ offers(Student, Course2) $\Rightarrow$ overlaps(Time1, Time2).

A3: $\forall$ Student, Course1, Time1, Course2, Time2.

holds(Course1, Time1) ^ holds(Course2, Time2) $\wedge$ during(Time1, Time2) ^offers(Student, Course1) $\wedge$ offers(Student, Course2) $\Rightarrow$ overlaps(Time1, Time2).

A4: $\forall$ Student, Course1, Time1, Course2, Time2.

holds(Course1, Time1) ^ holds(Course2, Time2) $\wedge$ starts(Time1, Time2) ^offers(Student, Course1) $\wedge$ offers(Student, Course2) $\Rightarrow$ overlaps(Time1, Time2).

A5: $\forall$ Student, Course1, Time1, Course2, Time2.

holds(Course1, Time1) ^ holds(Course2, Time2) ^ finishes(Time1, Time2) ^offers(Student, Course1) $\wedge$ offers(Student, Course2) $\Rightarrow$ overlaps(Time1, Time2).

A6: $\forall$ Course1, Time1, Dept1,Course2, Time2.

owns(Dept1, Course1) 1owns(Dept1, Course2) ^holds(Course1, Time1) ^ holds(Course2, Time2) sequals(Time1, Time2) sequals(Level1, Level2)

$\Rightarrow \rightarrow$ overlaps(Time1, Time2).

A7: $\forall$ Course1, Time1, Dept1, Fac1, Course2, Time2, Dept2. Fac2. owns(Dept1, Fac1, Course1) ^owns(Dept2, Fac2, Course2) $\Rightarrow \quad \rightarrow$ overlaps(Time1,Time2) $\quad \vee \quad \rightarrow$ during(holds(Course1, Course2)) .

A8: $\forall$ Course1, Time1, Course2, Time2, $\exists t$. holds(Course1, Time1) Aholds(Course2, Time2) $\wedge$ finishes(Time1, $t$ )^starts(Time2, $t) \Rightarrow$ meets(Time1, Time2).

A9: $\forall$ Course1, Time1, Dept1, Fac1, Course2, Time2, Dept2. Fac2. owns(Dept1, Fac1, Course1) ^owns(Dept2, Fac2, Course2) $\wedge \neg$ equals (Fac1, Fac2)

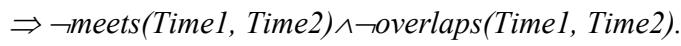

A10: $\forall$ Course1, Time1, Venue1, Course2, Time2, Venue2. holds(Course1, Time1) sholds(Course2, Time2) sequals (Venue1, Venue2) $\Rightarrow$-equals(Time1, Time2).

A11: $\forall$ Course1, Time1, Let, Camp1, Course2, Time2, Camp2. holds(Course1, Time1, Camp1) ^holds(Course2, Time2, Camp2) requals (Time1, Time2) ^equals (Camp1, Camp2) ^teaches (Let, Camp1) ^teaches (Let, Camp2) $\Rightarrow \neg$ overlaps (Time1, Time2) v $\neg$ meets (Time1, Time2)

A12: $\forall$ Course1, Time1, Camp1, Course2, Time2, Camp2. holds(Course1, Time1, Camp1) ^holds(Course2, Time2, Camp2) requals (Time1, Time2)^equals (Camp1, Camp2) $\Rightarrow \neg$ meets (Time1, Time2)

A13: $\forall$ Student, Course1, Time1, Dept1, Course2, Time2. offers(Student, Course1, Time1) ^offers(Student, Course2, Time2) ^owns(Dept1, Course1) ^ equals(Time1, Time2) $\wedge$ equals(Level1, Level2) $\Rightarrow \rightarrow$ overlaps(Time1, Time2).

A14: $\forall$ Student, Course1, Time1, Dept1, Course2, Time2. offers(Student, Course2, Course2) ^ holds(Course1, Camp1) ^ holds(Course2, Camp2) $\Rightarrow \neg$ meets(Time1, Time2) $\neg$ overlaps (Time1, Time2). 


\section{P. U. Usip et al. / Advances in Science, Technology and Engineering Systems Journal Vol. 2, No. 3, 1585-1591 (2017)}

A15: $\forall$ Student, Course1,Venue1, Time1, nos, $\exists$ Venue2, ccap.

offers(Student, Course1, Venuel) ^ holds(Course1, Venue1, Time1) $\wedge($ nos $>$ ccap $) \Rightarrow$ holds(Course1, Venue2)

\subsection{Weighting of Complexities}

The severity levels of complexities are denoted by $0 \%, 50 \%$ $70 \%$ and $100 \%$ respectively based on the sources of complexity (time, space and location).

\section{Overlapping Time:}

Overlapping time complexities includes five relations in Allen's Interval-based Temporal Relations: starts, finishes, overlaps, during and equals. In this paper, these five temporal relations are classified into two levels of complexities namely complete and partial. Complete overlap occurs if two or more courses offered by a group of Students begins and ends at the same time (Equals Relation - See Table 2) or the Start and End times of these course is within the start and end time of $c_{j}$ (During Relation - See Table 3), then a complete overlap of weight $100 \%$ has occurred. However, the During relation will not apply in this domain since the university system does not have 4-hour lecture period. For example, instances of equals and during relations are given in Tables 2 and 3 respectively.

Table 2: equals Relation

\begin{tabular}{|l|l|l|l|}
\hline 8:00 & $9: 00-10: 00$ & $10: 00-$ & $11: 00-12: 00$ \\
9:00 AM & AM & $11: 00 \mathrm{AM}$ & NOON \\
\hline \multicolumn{2}{|c|}{$c_{i}$} & & \\
\hline \multicolumn{2}{|c|}{$c_{j}$} & & \\
\hline
\end{tabular}

Table 3: during Relation

\begin{tabular}{|l|l|l|l|}
\hline 8:00 - & $9: 00-10: 00$ & $10: 00-$ & $11: 00-12: 00$ \\
9:00 AM & AM & $11: 00 \mathrm{AM}$ & NOON \\
\hline \multicolumn{3}{|c|}{$c_{i}$} \\
\hline \multicolumn{3}{|c|}{$c_{j}$} \\
\hline
\end{tabular}

A partial overlap is described using Allen's Interval-based Temporal Relations as follows; overlaps, starts and finishes shown in Tables 4, 5 and 6 respectively. These relations under partial overlap are assigned a complexity of $50 \%$. Examples of partial overlaps are given in Tables 4, 5 and 6

Table 4: overlaps Relation

\begin{tabular}{|l|l|l|l|}
\hline 8:00 9:00 AM & 9:00-10:00 & 10:00 - & 11:00- 12:00 \\
\hline \multicolumn{2}{|l|}{ AM } & 11:00 AM & NOON \\
\hline & $c_{i}$ & & \\
\hline
\end{tabular}

Table 5: starts Relation

\begin{tabular}{|c|c|c|c|}
\hline $\begin{array}{l}8: 00-9: 00 \\
\text { AM }\end{array}$ & $\begin{array}{l}9: 00-10: 00 \\
\text { AM }\end{array}$ & $\begin{array}{l}10: 00 \\
11: 00 \mathrm{AM}\end{array}$ & $\begin{array}{l}11: 00-12: 00 \\
\text { NOON }\end{array}$ \\
\hline \multicolumn{4}{|c|}{$c_{i}$} \\
\hline$c_{j}$ & & & \\
\hline
\end{tabular}

Table 6: finishes Relation

\begin{tabular}{|l|l|l|l|}
\hline $\begin{array}{l}\text { 8:00 9:00 AM } \\
\text { 9: }\end{array}$ & $\begin{array}{l}9: 00-10: 00 \\
\text { AM }\end{array}$ & $\begin{array}{l}10: 00- \\
11: 00 \mathrm{AM}\end{array}$ & $\begin{array}{l}\text { 11:00- 12:00 } \\
\text { NOON }\end{array}$ \\
\hline \multicolumn{2}{|c|}{$c_{i}$} & & \\
\hline & \multicolumn{2}{|c|}{$c_{j}$} & \\
\hline
\end{tabular}

In the resolved overlap, the desired Allen's interval-based temporal relation for the resolution of overlapping time complexity is before in Table 7 and Table 8 . When course $c_{i}$ is before course $c_{j}$ a $0 \%$ complexity is recorded.
Table 7: before Relation (A)

\begin{tabular}{|c|c|c|c|}
\hline $\begin{array}{l}8: 00 \quad- \\
9: 00 \mathrm{AM}^{-}\end{array}$ & $\begin{array}{l}9: 00-10: 00 \\
\text { AM }\end{array}$ & $\begin{array}{l}10: 00 \quad- \\
11: 00 \mathrm{AM}\end{array}$ & $\begin{array}{l}11: 00-12: 00 \\
\text { NOON }\end{array}$ \\
\hline \multicolumn{4}{|c|}{$\mathrm{c}_{\mathrm{i}}$} \\
\hline & & \multicolumn{2}{|r|}{$c_{j}$} \\
\hline \multicolumn{4}{|c|}{ Table 8: before Relation (B) } \\
\hline $8: 00$ & $9: 00-10: 00$ & 10:00 & $11: 00-12: 00$ \\
\hline 9:00 AM & $\mathrm{AM}$ & 11:00 AM & NOON \\
\hline \multicolumn{4}{|c|}{$c_{i}$} \\
\hline & & & $c_{j}$ \\
\hline
\end{tabular}

2. Meeting Time Complexity

If courses $c_{i}$ and $c_{j}$ hold in geographically dispersed Venues $\left(R_{n} U_{m}\right.$, $\left.R_{n+l} U_{m+1}\right)$ and it takes a student time $\boldsymbol{t}_{\boldsymbol{n}}$ to move from venue $R_{n} U_{m}$ to $R_{n+1} U_{m+1}$, there exist a time complexity if course $c_{j}$ starts immediately course $\boldsymbol{c}_{\boldsymbol{i}}$ ends as shown in Table 9 .

Table 9: Meeting Time Complexity (100\%)

\begin{tabular}{|c|l|l|l|}
\hline $8: 00-$ & $9: 00-10: 00$ & $10: 00-$ & $11: 00-12: 00$ \\
$9: 00$ AM & AM & $11: 00$ AM & NOON \\
\hline & & & \\
\hline \multicolumn{2}{|c|}{$c_{i}$} & & \\
\hline & & \multicolumn{2}{c|}{$c_{j}$} \\
\hline
\end{tabular}

The $70 \%$ is for time to reach the venue and $100 \%$ is if there is additional time for the student to settle in the class before the actual lecture start time, an additional $30 \%$ weight is added. A $70 \%$ and a $100 \%$ resolution of the Meeting time complexity is as shown in Tables 10 and 11

Table 10: 70\% Resolved Meeting Time Complexity

\begin{tabular}{|l|l|l|l|}
\hline 8:00-9:00 & $9: 00-10: 00$ & $10: 00-11: 00$ & $11: 00-12: 00$ \\
AM & AM & AM & NOON \\
\hline \multicolumn{2}{|l|}{$c_{i}$} & & $c_{j}$ \\
\hline & & & \\
\hline
\end{tabular}

Table 11: 100\% Resolved Meeting Time Complexity

\begin{tabular}{|l|l|l|l|}
\hline $8: 00-9: 00$ & $9: 00-10: 00$ & $10: 00-11: 00$ & $11: 00-12: 00$ \\
AM & AM & AM & NOON \\
\hline$c_{i}$ & & & $c_{j}$ \\
\hline & & & \\
\hline
\end{tabular}

\section{Implementation Results and Discussions}

The timetable showing schedules for two departments located at different campuses are used for the implementation of the proposed system.

These two departments offer common courses - CSC 211, STA 211, CSC 111. The natures of complexity are (meeting and overlapping times) clearly. Analysis of existing system shows the course under study, CSC 211 with Geo-informatics students in 300 level, who may be carrying over the course. It also handles the distance apart between the two campuses, being the venue for these two courses. Another case considers a complete overlap where CSC 211 and STA 211 from two different departments at two different venues, though in the same campus. Here, students of both departments are offering CSC 211. The analysis of these complexity levels with given assigned weights on the identified complexities is as shown in Table 12.

Table 12: Complexity weights of the existing time schedules

\begin{tabular}{|c|c|c|}
\hline Case No & Complexity Type & Complexity Weight (\%) \\
\hline 1 & Meeting Time & 100 \\
\hline 2. & $\begin{array}{c}\text { Overlapping Time } \\
\text { (equals) }\end{array}$ \\
\hline
\end{tabular}




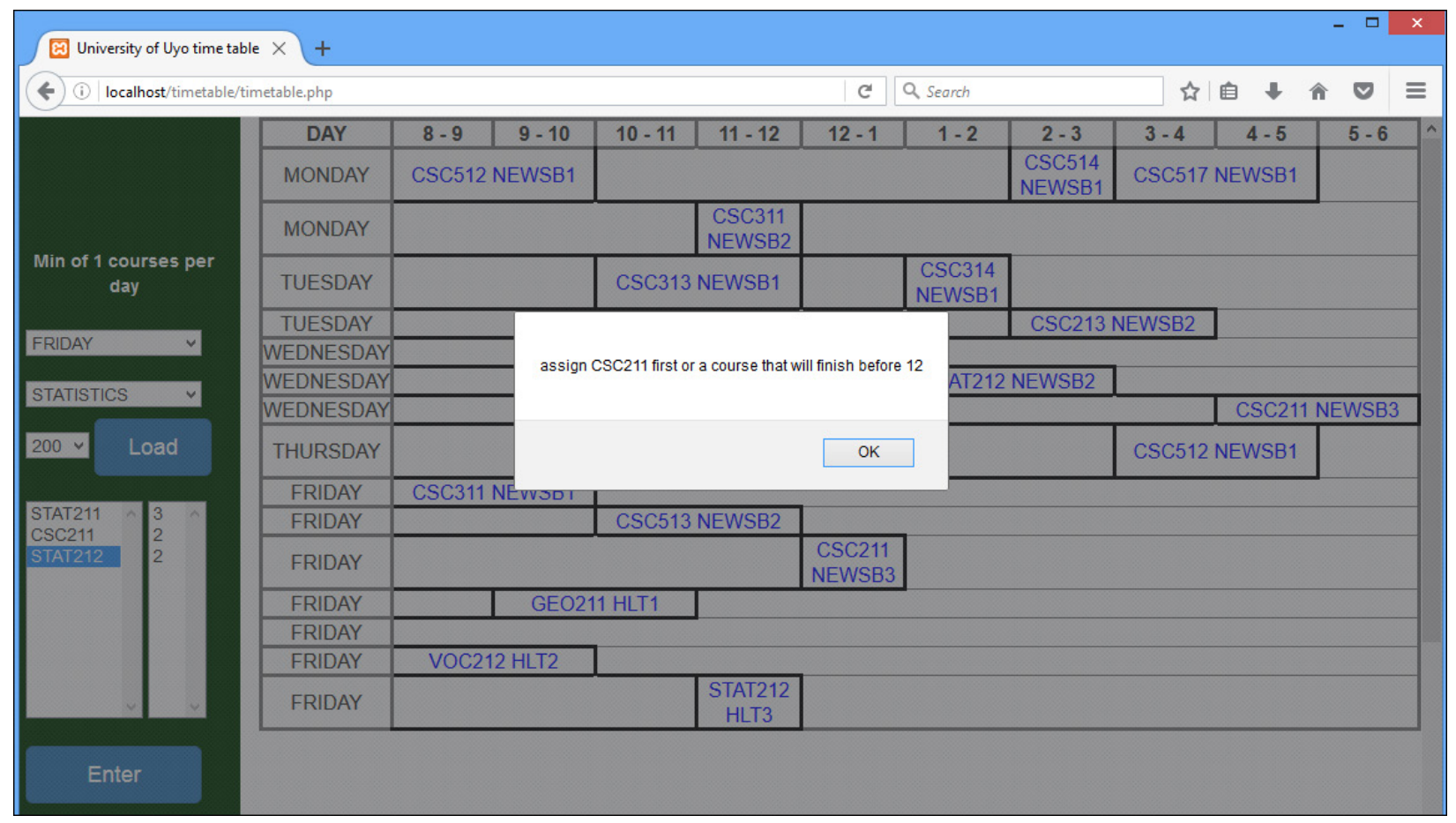

Figure. 5: Active Resolution of Meeting Time Complexity.

\subsection{Resolutions with proposed Time Scheduling system}

To resolve the time schedules, the complexity weights of the two cases should be $30 \%$ and $0 \%$ for meeting time and overlapping time respectively. The screen shots in Figure 5 gives the resolution of the meeting time complexity for the scheduled GEO 211 and CSC 211. The screen shot also shows a prompt to reschedule the STA 212 course as shown on the white pop-up window. That is the overlapping time complexity resolution, where the prompt calls for the relocation of the statistics (STA) course resulted. This is because CSC 211 is offered by many other departments, thereby having increased level of inter-dependency than the STA 212 course.

\section{Conclusion}

The proposed optimized time scheduling system analyzes any given existing time schedule and identifies the complexity types in existence. It provides the users the window to reschedule any time with identified complexity to obtain an optimized time schedule as shown in this paper. The rules in the reasoner are based on Allen's interval-based temporal relations as well the domain specific relations. Knowledge management as seen in the university timetabling complexities is possible with the mapping of the departmental timetable ontologies shown in the ontograf with all other required resources in the databases of fact. As a further work, the formal model that describes how the embedded semantics in the given rules are used for inferencing will be implemented on the ontology.

\section{References}

[1] P. U. Usip and M. M. Ntekop. "The use of ontologies as efficient and intelligent knowledge management tool", In Proceedings of Future Technologies Conference. 6-7 December 2016, San Francisco. pp 626-631. DOI: $10.1109 /$ FTC.2016.7821671
[2] M. E. Saleh. Semantic-based query in relational database using ontology. Journal on Data and Knowledge Engineering. 2011.

[3] J. Allen. Maintaining knowledge about temporal intervals. Communications of the ACM 26. 1983. (11): 832-843.

[4] P. U. Usip and E. Umoren. Towards a formal interval-based temporal ontology for an optimized timetable management. In Proceedings of Transition from Observation to Knowledge to Intelligence Conference (TOKI 2016), Lagos. pp. 293-304

[5] K. H. Shafa'amri and J. O. Atoum. A framework for improving the performance of ontology matching techniques in semantic web. International Journal of Advanced Computer Science and Applications, 2012. 3(1) 8-14.

[6] B. Coppin. Artificial Intelligence Illuminated. Jones and Bartlett Publishers, Inc., 2004. Sudbury

[7] D. Waltz. Artificial Intelligence: realizing the ultimate promises of computing, AI magazine. 1997) 18, 49-52

[8] I. M. Jurisica and J. Eric. Ontologies for knowledge management: an information systems perspective. Knowledge and Information Systems. 2004. 6, 380-401. DOI 10.1007/s10115-003-0135-4

[9] D. Abramson. Constructing school timetable using simulated annealing: sequential and parallel algorithm. 1991

[10] E. K. Burke and S. Petrovic. Recent research directions in automated timetabling. European Journal of Operational Research. 2002. 140. 266-280.

[11] A. O. Modupe, O. E. Olusayo and O. S. Olatunde. Development of a university lecture timetable using modified genetic algorithm approach. International Journal of Advance Research in Computer Science and Software Engineering. 2014. 4. 163-168.

[12] J. R Hobb and F. Pan. An ontology of time for semantic web. 2004. 3, 6685.

[13] M. Hamalatha, V. Uma and G. Aghila. Time ontology with reference event based temporal relation (RETR). International Journal of web and Semantic Technology (IJWSSY). 2012. 3. 